\title{
HISTORIA DE LA JUSTICIA MAYA EN LA PENÍNSULA DE YUCATÁN
}

\author{
YUCATECAN MAYA JUSTICE IN THE PENINSULA OF YUCATÁN
}

\section{Resumen}

$\mathrm{E}$

l objetivo del presente artículo es presentar los cambios y continuidades de lo que se denomina justicia maya, como esas prácticas de solución de conflictos ancestrales que se han modificado con el paso de los años. La metodología que se emplea es de corte cualitativo y se sustenta en el método de la larga duración histórica en la cual traza una línea en el tiempo que va desde la época prehispánica hasta el Estado nacional. Esto ayuda a tener como hallazgos los cambios en la forma en que se ejerció la justicia maya en el tiempo, además de lo complejo que es comprender desde una sola perspectiva. Con ello se concluye que la justicia maya transitó por eventos que fueron coyunturales para su desarrollo, que se basa en usos y costumbres y que no escapa de la influencia de normas, códigos e instituciones que le imponen límites, la trastocan y muchas veces modifican sus prácticas.

Palabras clave: justicia; historia; pluralismo.

\section{Abstract}

he objective of this article is to present the changes and continuities of what is called Mayan justice as those ancient conflict resolution practices that have been changing over the years. The methodology used is of a qualitative nature and is based on the historical long-term method in which it traces a line in time that goes from pre-Hispanic times to the National State. This helps having as findings the changes in the way Mayan justice was exercised over time, as well as how complex it is to understand it from a single perspective. With this it is concluded that Mayan justice went through events that were circumstantial for its development, that it is based on uses and customs and that it does not escape the influence of norms, codes and institutions that impose limits on it, disrupt it and often modify its practices.

Key words: justice; history; pluralis.

1 Licenciado en Derecho por la UADY, Maestro en Trabajo Social por la UNAM, Maestro en Desarrollo Regional por el Tecnológico Nacional, Doctor en Ciencias Sociales. Adscrito al Instituto Electoral y de Participación Ciudadana de Yucatán, es miembro del Sistema Nacional de Investigadores y del Servicio Profesional Electoral Nacional, México, boliojuridico@gmail.com, ORCID: 0000000177568858.

2 Licenciado en Derecho por la UADY, Maestro y Doctor en Historia por el CIESAS. Adscrito al Instituto Electoral y de Participación Ciudadana de Yucatán, es miembro del Sistema Nacional de Investigadores y del Servicio Profesional Electoral Nacional, México, boliojuridic@hotmail.com. ORCID: 0000000168685585. 


\section{Introducción}

Debido a los conflictos derivados de la interlegalidad e interculturalidad vinculada a nuevas leyes que buscan delimitar la justicia maya. No se puede pasar por alto el necesario estudio de aspectos históricos sobre la justicia maya. Para entender de forma más acertada una sociedad es indispensable conocer la historia y contexto que han significado transformaciones en la manera en que se ejerce la justicia. El presente artículo, tiene como objetivo central explorar la justicia maya a través del tiempo, exponiendo los cambios y continuidades de lo que se denomina justicia maya.

La sociología puede beneficiarse de la historia, a través de formas de interpretación y teorías. La diferencia de ambas disciplinas está en el enfoque, pues la primera explica los acontecimientos sociales de forma transversal sincrónica y en la segunda, su objeto de estudio es de corte longitudinal diacrónico, la imbricación de ambas acontece al desentrañar aspectos sociales y culturales de los grupos humanos. El sociólogo puede encontrar paralelismos entre la experiencia histórica de nuestra sociedad y la experiencia contemporánea de sociedades más primitivas. Ambas ciencias tienen mucho de que complementarse y es inútil pensar que, en el distanciamiento de sus enfoques, un análisis estructural serio de las sociedades del pasado nos permita comprenderlas a cabalidad en el presente. La hipótesis del trabajo consiste en que a pesar de hacer un estudio en la larga duración histórica, es posible identificar cambios y continuidades en la justicia maya yucateca.

La justicia maya es entendida como una forma de dar solución a conflictos dentro de una comunidad y que ha existido a lo largo de la historia, pero como cualquier institución social se ha ido transformando con el transcur- 
so de los años (Bolio y Bolio, 2017, p. 49). En este tenor, la investigación se centra en lo que se entiende por justicia maya de Yucatán en la larga duración que abarca varios siglos de historia, que es contrastada con un acercamiento de corte antropológico jurídico en lo que acontece en el Yucatán actual, el objetivo es justamente dar cuenta de todos los procesos históricos-jurídicos que han venido transformando lo que se entiende por justicia maya, como se imbrica el concepto endógeno de la justicia maya y las transformaciones que se van dando en las instituciones y agentes, dando para ello es menester recurrir a la larga duración que permite articular representaciones y símbolos de la cultura y el derecho, por lo cual es menester cuestionarse, ¿de dónde viene la justicia maya?, ¿cuáles fueron los cambios?, ¿cómo se expresa en la sociedad maya yucateca?, ¿podemos hablar de una verdadera justicia maya?. El artículo está integrado de la siguiente forma: periodo prehispánico, periodo colonial, periodo del Estado nacional, metodología, resultados y discusión y conclusiones.

\subsection{Delimitación espacial}

La península de Yucatán fue descubierta en 1508 por Juan de Solís y Vicente Yáñez de Pinzón. En 1511, Gonzalo Guerrero y Gerónimo de Aguilar sobrevivieron a un temporal y se quedaron en territorio yucateco. La costa de Yucatán fue explorada tiempo después por las expediciones de Francisco Hernández de Córdoba en 1517, Juan de Grijalva en 1518 y Hernán Cortés en 1519. Cortés se situó en Cozumel donde rescató a Gerónimo de Aguilar, quien posteriormente sirvió de intérprete en la campaña de conquista de México. El otro náufrago, Gonzalo Guerrero, continuó viviendo entre los mayas habiéndose casado con la hija del cacique de Chetumal. La península de Yucatán separa el Golfo de México del mar Caribe, que abarca tres estados mexicanos y partes de Belice y Guatemala.

\subsection{Periodo prehispánico}

Sobre la justicia maya prehispánica se tienen pocas fuentes primarias que permiten recrear cómo funcionaba según sus fundamentos ontológicos. No obstante, a través de textos como el de Ana Luisa Izquierdo (1981), sumados a las fuentes arqueológicas, crónicas y relaciones del siglo XVI, es posible recrear el sistema jurídico maya prehispánico, por normas y principios generales, algunos de dichos principios fueron la oralidad y rapidez de los procesos.

Los mayas tuvieron un sistema de derecho sólidamente estructurado. En la punta de la pirámide de la estructura jurisdiccional maya se encontraba el halachuinic, señor supremo, quien legislaba, sentenciaba, con un amplio margen de discrecionalidad en la aplicación del poder jurisdiccional para funcionarios como asuntos que llega- 
ran ante él. Para desempeñar sus funciones, estaba auxiliado por un supremo consejo. El halachuinic, podía delegar parte de su poder en los señores menores (batabes), los españoles los equipararon con caciques, un término empleado en las Antillas para designar a los señores. En esos casos, el batab servía como enlace con el halachuinic y controlaban territorios importantes.

El cacique batab, que significa "jefe", tenía autoridad política en cada poblado, en el campo del derecho podía legislar, juzgar o sancionar en su comunidad, con los límites que le exigía la sujeción a un gobernador más poderoso. Los batabes dividían al pueblo por sus barrios a modo de "colaciones" y nombraban un hombre rico y hábil para que tuviera a su cargo cada uno de ellos, se encargaban de recolectar el tributo y de congregar a las personas en sus parcialidades (De la Garza, 2008, p. 100).

El que recibía las demandas era el ah ku$l e l$, traducido por el diccionario de Motul como "cierto oficial de la república", las personas que se acercaban al ah kulel para iniciar una causa llegaban con regalos a manera de pago por los servicios a prestar, quien las turnaba posteriormente al batab, en la base de la pirámide estaba el tupil, era el alguacil que siempre estaba ante los jueces (Izquierdo, 1981, pp. 57-60).

El ah kulel, auxiliado por testigos, abogados y con la participación de miembros de la comunidad, podía resolver asuntos de rango menor, si el batab lo consideraba po- día intervenir en asuntos del ah kulel, si se trataba de delitos graves o asuntos de mayor relevancia se turnaban al batab, quien siempre auxiliado de un consejo resolvía, misma situación que se observa en el caso del halachuinic. Hablamos de que el proceso judicial maya tenía un examen riguroso de las pruebas entre las cuales resaltan sin duda las presunciones y la confesión. Las sentencias consideraban los daños económicos, la clase social, el sexo y la edad del culpable. Se solía tolerar más los delitos de un miembro del pueblo común que de una persona de elevada condición social, no admitían medios de impugnación. Las atenuantes de los delitos eran la impericia, negligencia o el estado emocional y las agravantes fueron en esencial la reincidencia delictiva (Izquierdo, 1981, pp. 61-63).

Las Relaciones Geográficas de Yucatán también hablan de la pena de muerte para los adúlteros y que los ladrones eran castigados con esclavitud, "a los homicidas mataban, y si era persona poderosa le penaban la hacienda o daba un esclavo en recompensa del muerto (sic)" (De la Garza, 2008, p. 73). Diego de Landa relata puntos importantes sobre las penas y castigos que se imponían entre los mayas a los que cometían los delitos de homicidio, adulterio y robos:

Que a esta gente les quedó desde Mayapán la costumbre de castigar a los adúlteros de esta manera: hecha la pesquisa 
y convencido alguno de adulterio, se juntaban los principales en casa del señor, y traído el adulto abátanle a un palo y le entregaban al marido de la mujer delincuente; si él le perdonaba, era libre; si no, le mataba con una piedra grande, que le dejaba caer en la cabeza desde una parte alta; a la mujer por satisfacción bastaba la infamia que era grande, y comúnmente por esto las dejaban. La pena de homicidio, aunque fuese casual, era morir por insidias de los parientes, o si no, pagar el muerto. El hurto pagaba y castigaban, aunque fuese pequeño, con hacer esclavos y por eso hacían tantos esclavos, principalmente en tiempo de hambre, y por eso fue que nosotros los frailes tanto trabajamos en el bautismo: para les diesen libertad. Y si eran señores o gente principal, se juntaba el pueblo y prendido el delincuente le labraban el rostro desde la barba hasta la frente, por los dos lados, en castigo que tenían por grande infamia (De Landa, 2012, p. 61).

Del relato señalado es claro que el derecho penal maya fue un derecho con penas bastante estrictas: como la de muerte, esclavitud y vergüenza pública. Como se observa de lo expuesto por Landa como lo que señala Antonio Salcedo, la administración de justicia entre los mayas era severa, expedita y definitiva. Existió una clara diferenciación entre dolo y culpa, esta última la aplicaban en los casos de homi- cidio, incendio, suicidio, etcétera. En materia de derecho civil, era posible recurrir al divorcio y al repudio, la ley se aplicaba igual a la gente y al pueblo. En las leyes sobre herencia eran tan precisas que no hacía falta testar, heredaban primero los hijos y, en su defecto, los parientes más cercanos, pero nunca las hijas (Salcedo, 2009, p. 156).

\subsection{Periodo colonial}

Dentro del esquema colonial, convivieron durante tres siglos, tres órdenes normativos diferentes, el derecho castellano (aquel que se legisló en Castilla para los territorios españoles), el derecho indiano (aquel que legislaba situaciones relativas a las Indias) y el derecho consuetudinario indígena. Los tres dieron lugar a un sistema jurídico colonial bastante complejo, lleno de jurisdicciones, procedimientos, recursos e instancias políticas y judiciales perfectamente jerarquizadas. El derecho castellano era de carácter supletorio al derecho indiano, exceptuando la materia procesal donde la legislación indiana fue verdaderamente pobre. El derecho consuetudinario tuvo un peso específico importante dentro de la jurisdicción de los pueblos. Viendo las autoridades hispanas ciertas características del derecho indígena se crearon dentro del territorio indiano diversos juzgados de indios, con el fin de fungir como defensorías y como tribunales que intentaban copiar la celeridad en los procesos de los naturales. 
El choque cultural trajo consigo nuevas prácticas y desembocó en un pluralismo jurídico que pudo pervivir por el reconocimiento que hizo la Corona española a la jurisdicción de los pueblos de indios, en los cuales pudieron llevar a cabo procesos judiciales acorde con sus usos y costumbres, siempre y cuando no contrariaran las normas del derecho castellano y de la religión católica.

En términos generales podemos decir que la justicia maya en tiempos coloniales fue permitida por ley, aunque limitada en cuanto a competencia y alcances más allá del pueblo de indios, esta justicia maya colonial debe ser entendida como un orden jurídico nutrido del derecho maya prehispánico, el derecho castellano y el derecho indiano. Los mecanismos precisamente radicaron en la figura de pueblo de indios, el cacique, el gobernador de indios y el cabildo indígena. El proceso judicial sumario era la forma de todo juicio donde intervinieron los indios, como parte de respeto a los usos y costumbres de los pueblos indígenas y la difusión del derecho indiano entre los naturales fueron medidas alentadas por la Corona con el fin de mejorar el acceso de los indios a la justicia.

Una de las primeras dudas que surgieron a inicios del siglo XVI fue la cuestión relativa a los derechos de los indígenas. Cuestión que gracias a la postura de derecho natural de Las Casas y Zorita pudo concretizarse con la coyuntura de la implanta- ción de las Leyes Nuevas de $1543,{ }^{3}$ con estas los indígenas gozaron del reconocimiento de mayores derechos y de ser considerados vasallos del rey, prueba de esto es que hubo disposición expresa en el sentido de que los usos y costumbres indígenas debieron respetarse en los negocios jurídicos de la Nueva España, siempre y cuando no fuera contrario a lo que determinaran las leyes fundamentales de la Corona y la religión católica, una real cédula señalaba:

Ordenamos y mandamos, que las leyes y buenas costumbres, que antiguamente tenían los indios para su buen gobierno y policía, y sus usos y costumbres observadas y guardadas después que son cristianos, y que se encuentran en nuestra sagrada religión, ni con las leyes de este libro, y las que se han hecho y ordenado de nuevo se guarden y ejecuten, y siendo necesario, por la preferente las aprobamos y confirmamos, con tanto que no podemos añadir lo que fuéremos servido, y nos pareciere que conviene al servicio de Dios nuestro Señor, y al nuestro y a la conservación y policía cristiana, de los naturales de aquellas provincias, no perjudicando a lo que tienen hecho, ni a

3 Emitidas por Felipe II en Valladolid, el 4 de junio de 1543, a las cuales corresponde el nombre de Leyes y Ordenanzas nuevamente hechas por su Majestad para la gobernación de las Indias y buen tratamiento y conservación de los Indios, que se han de guardar en el Consejo y Audiencias reales que en ellos residen, y por todos los gobernadores y jueces y personas particulares de ellas. 
las buenas y justas costumbres y estatutos suyos (ADLP, 1680). ${ }^{4}$

Conforme a las fuentes revisadas, se traduce en un pluralismo jurídico consistente en la imbricación entre derecho castellano, derecho indiano y derecho consuetudinario maya, que se desarrolló por dos grupos de autoridades reconocidas por las Leyes de Indias, las castellanas en primer orden de prelación y las indígenas. Uno de los problemas que existió fue que cuando el caso judicial maya arribó ante una autoridad civil (corregidor, alcalde, gobernador, etcétera), lo juzgado previamente por el juez maya se limitó a ser tomado como presunciones, indicios o testimonios dentro del juicio de orden común, puesto que las sentencias o resoluciones indígenas no correspondieron a una instancia dentro de la justicia del derecho castellano (Bolio J. , 2012, p. 103).

La ley 12, título 7, libro 7 de la Recopilación de Leyes de Indias de 1680 determinó con claridad dos de los niveles jurisdiccionales que convivían en el territorio indiano:

\section{La jurisdicción criminal que los caciques} han de tener en los indios de sus pueblos, no se ha de entender en causas criminales, en que hubiere pena de muerte, mutilación de miembro, o algún otro castigo atroz, quedando siempre reser-

4 ADLP: Ley 4, título 1, libro 2, Recopilación de Leyes de Indias de 1680. vado para Nos, y nuestras Audiencias, y Gobernadores la jurisdicción suprema, así en lo civil, como en lo criminal, y el hacer justicia, donde ellos no la hicieren (ADLP, 1680). ${ }^{5}$

Las Leyes Nuevas de 1543 fueron un punto coyuntural en cuanto al reconocimiento de derechos, aunque esto no significó por supuesto que diversas quejas siguieran existiendo por el maltrato a los indios, así se manifestó en diversas cédulas y cartas enviadas al rey durante toda la colonia.

Yucatán fue una gobernación, alcaldía mayor, capitanía general y a fines de la colonia una intendencia. El territorio era amplio y estaba integrado por los actuales estados mexicanos de Yucatán, Campeche, Quintana Roo y Tabasco, así como el norte de Belice. Dentro de toda esta jurisdicción, el gobernador fue el encargado de impartir justicia como máximo depositario de la misma, y a su vez auxiliado por diversos órganos religiosos, civiles, fiscales y entre ellos, los alcaldes de los pueblos de indios. La jurisdicción de las repúblicas de indios se aplicó única y exclusivamente en los poblados por autoridades indígenas. Pues como hemos dicho, tuvieron el reconocimiento legal de emplear el derecho consuetudinario y de juzgar delitos menores según el derecho castellano.

5 ADLP, Ley 12, título 7, libro 7, Recopilación de Leyes de Indias de 1680. 
En Yucatán una institución verdaderamente importante en cuanto a la aplicación del derecho indígena fue el juzgado general de indios, cuya competencia era de primera instancia para tratar casos entre indios, o de españoles contra indios, atendiendo a la población indígena tanto de manera individual como colectiva. Se debía procurar llevar los asuntos de forma sumaria, es decir con la mayor brevedad posible, quizá para asemejarse en cierta forma con el derecho consuetudinario indígena que resolvía los asuntos de forma breve, oral y con sanciones como la vergüenza pública (Borah, 1996, pp. 120, 121).

Algunos estudios como los de Cunill (2012) y Solís (2013) han demostrado que el juzgado en Yucatán funcionó generalmente como defensoría de indios. El juzgado general de indios en Yucatán estuvo integrado por distintos cargos bien establecidos como, abogado, protector, defensor, intérpretes, escribanos, asesor letrado, fiscal, entre otros funcionarios.

El juzgado evolucionó en la segunda mitad del siglo XVI, en un inicio los funcionarios eran civiles y religiosos, para luego especializarse y tener funciones más o menos definidas. Fue una constante pues las diversas instituciones se fueron perfeccionando. Se consideró a la numerosa población maya, "la verdadera fuente de riqueza, cuyo esfuerzo era demandado tanto por encomenderos y vecinos como por religiosos, eclesiásticos y el mismo go- bierno". Si bien los encomenderos debían velar por la protección de los naturales, "la Audiencia correspondiente, el Consejo de Indias y el propio rey llegarían a la conclusión de que ese deber no se cumplía”. Por ello, fue necesario nombrar a un defensor de los indios cuyas funciones fueran independientes del gobernador provincial. Ello respondía a política de la Corona de preservación de los naturales (Solís, 2013, p. 80).

La defensoría fue una labor donde colaboraban intérpretes, escribanos, procuradores y abogados. Si bien se tendió a la especialización de la defensoría, los defensores ocuparon diversos cargos como escribanos, alguaciles, procuradores generales, alcaldes, regidores y corregidores, además de que ostentaron grados militares como sargento mayor o maestre de campo, también las quejas contra ellos fueron diversas como contra los encomenderos, todo ello sugiere que el cargo fue usado como peldaño institucional (Cunill, 2012, pp. 190-220).

Es claro que la Corona tenía presente el pluralismo que se vivía en la región; $\mathrm{Cu}$ nill ha apuntado que, por ejemplo, el oficio de intérprete fue institucionalizado en los juzgados del Nuevo Mundo, porque permitió que fuesen aceptadas las lenguas autóctonas en los pleitos civiles y criminales, lo cual se insertaba dentro de la cultura política de la época, en la que la negociación entre el rey y los distintos cuerpos que componían la sociedad formaba parte 
del ejercicio de la soberanía (Cunill, 2012, pp. 22-24). Durante los tres siglos de la colonia, las instituciones de justicia para los mayas y de los mayas pervivieron, incluso ante las reformas borbónicas del siglo XVIII. No obstante, la segunda mitad del siglo XVIII fue una etapa sumamente complicada pues estuvo marcada por transformaciones que afectaron gravemente los haberes de los pueblos indígenas, sobre todo por el incremento en la venta de tierras municipales y privadas de los indios a los estancieros; ventas de alguna manera forzosas para poder afrontar deudas de tributos y otros gastos. De tal suerte que la crisis irreversible en la que entraron los pueblos y las élites locales mayas a causa del impulso del gobierno colonial a la ganadería y la agricultura comercial, llevaron a rebeliones como la de Jacinto Uc en 1761 (Bracamonte y Solís, 2005, p. 27).

\subsection{Periodo del Estado nacional decimonómico} En el México independiente, en el siglo XIX los cambios se dieron en el tenor de las diversas constituciones que rigieron al país y que aprovecharon los gobiernos de los pueblos de indios para instaurar los ayuntamientos. En este periodo empiezan a surgir nuevas estructuras de gobierno y administración como resultado de un cambio de paradigma ideológico (del colonialismo al liberalismo), pero aquellas se asientan en un entorno sociopolítico "en que el que aún siguen en función antiguas estructuras, las cuales coexistirían -formal o informalmente- con las nuevas medidas como respuesta a circunstancias específicas y con propósitos determinados” (Peraza, 2014, p. 39).

$\mathrm{Al}$ respecto, Daniela Marino, en el marco de su estudio sobre la cultura jurídica de los campesinos indígenas del centro de México durante el Segundo Imperio, asevera que:

En un proceso de formación y consolidación del estado como el que experimentaba México [...] las culturas jurídico-políticas de la mayoría de los actores de una sociedad todavía fragmentada y heterogénea, se conformaban por elementos modernos tanto como por ideas y prácticas de antiguo régimen. La defensa de esta cultura política de antiguo régimen -en la cual la justicia, como valor y como estrategia, ocupaba un lugar prominente- era necesaria para la subsistencia de los pueblos y otros grupos como actores colectivos, y diversas coyunturas obligaron a sincretismos y negociaciones también diferentes (Marino, 2006, p. 1356).

El discurso del liberalismo en la esfera de la justicia se basaba en la homogeneización y unificación de la realidad jurídica, de modo que esta "comienza y termina en el ámbito legal” volviéndose el derecho singular (en contraposición al derecho plural colonial) y sinónimo de ley, esto 
explica el proceso codificador en México (Speckman, 2006).

Una de las aportaciones más importantes de la Constitución de Cádiz de 1812 fue el municipio pues esta:

Convirtió al municipio -o mejor dicho, a los que habitaban en las ciudades, villas y pueblos- con su participación, en piedra de toque para legitimar el orden ideal que propondrían los diversos órganos constituyentes a lo largo del siglo XIX. Desde entonces, el municipio -por más que no se le llame así en un principio- fue adquiriendo una importancia de primer orden. A partir de 1812, es en el ámbito municipal donde se regatearían los recursos materiales, se organizarían las elecciones locales y generales y se legitimarían o desaprobarían las autoridades del futuro Estado nación (Guemez, 2007, p. 97).

En suma, el ayuntamiento constitucional se convirtió en el órgano primordial de gobierno local y fue el eje que guio la reforma municipal llevada a cabo por la Constitución de Cádiz. Cabe señalar, sin embargo, que, si bien "el ayuntamiento se instaura para descentralizar el poder antes concentrado en la monarquía y otorgar un mayor control a la población local sobre la gestión política de sus municipios, es en última instancia un instrumento del nuevo Estado en formación (sic)" (Peraza, 2014, p. 45).

En la siguiente tabla se expone la conformación de los ayuntamientos en Yucatán desde 1825 hasta 1862, donde se observa cómo se va incorporando la figura del juez de paz desde la época del Estado nación, y cómo el juez de paz en el devenir histórico se homogeniza con el juez indígena colonial, o bien el cacique, cuestión que demuestra desde nuestro punto de vista el triunfo del Estado nacional.

Los ciudadanos (incluyendo los indígenas) que cumplían los anteriores requisitos tenían un grado amplio de participación en el gobierno municipal bajo el sistema federal (Tapia, 1985, pp. 150-152). 
Tabla 1. Órganos y funcionarios municipales en Yucatán, 1825-1862

\begin{tabular}{|c|c|c|c|c|c|}
\hline 1825 & 1835 & 1841 & 1850 & 1853 & 1862 \\
\hline $\begin{array}{l}\text { Ayuntamientos } \\
\text { (alcaldes, regido- } \\
\text { res y síndicos) }\end{array}$ & $\begin{array}{l}\text { Ayuntamientos } \\
\text { (alcaldes, regido- } \\
\text { res y síndicos) }\end{array}$ & $\begin{array}{l}\text { Ayuntamientos } \\
\text { (alcaldes, regido- } \\
\text { res y síndicos) }\end{array}$ & $\begin{array}{l}\text { Ayuntamientos } \\
\text { (alcaldes, regido- } \\
\text { res y síndicos) }\end{array}$ & $\begin{array}{l}\text { Ayuntamientos } \\
\text { (alcaldes, regido- } \\
\text { res y síndicos) }\end{array}$ & $\begin{array}{l}\text { Ayuntamientos } \\
\text { (alcaldes, regido- } \\
\text { res y síndicos) }\end{array}$ \\
\hline $\begin{array}{c}\text { Juntas } \\
\text { municipales } \\
\text { (alcaldes concilia- } \\
\text { dores y vocales) }\end{array}$ & Jueces de paz $^{6}$ & $\begin{array}{c}\text { Alcaldes } \\
\text { municipales }\end{array}$ & Jueces de paz & $\begin{array}{l}\text { Comisarios } \\
\text { municipales }\end{array}$ & $\begin{array}{c}\text { Juntas } \\
\text { municipales } \\
\text { (alcaldes concilia- } \\
\text { dores y vocales) }\end{array}$ \\
\hline $\begin{array}{c}\text { Alcaldes } \\
\text { auxiliares }\end{array}$ & & Jueces de paz & $\begin{array}{l}\text { Alcaldes } \\
\text { auxiliares }\end{array}$ & $\begin{array}{c}\text { Comisarios } \\
\text { auxiliares }\end{array}$ & $\begin{array}{l}\text { Comisarios } \\
\text { municipales }\end{array}$ \\
\hline & & $\begin{array}{c}\text { Alcaldes } \\
\text { auxiliares }\end{array}$ & $\begin{array}{l}\text { Repúblicas } \\
\text { de indígenas }\end{array}$ & $\begin{array}{l}\text { Repúblicas } \\
\text { de indígenas }\end{array}$ & $\begin{array}{l}\text { Alcaldes } \\
\text { auxiliares }\end{array}$ \\
\hline
\end{tabular}

Fuente: Peraza, 2014, pp. 49-50.

En 1840, con la vuelta al federalismo y la promulgación de la Constitución yucateca de 1841, los cargos municipales se ocuparían de nuevo a partir de un sistema de elecciones directas. Los órganos municipales vigentes conservaron los ayuntamientos en las ciudades, villas y cabeceras de partido y se nombraron alcaldes municipales en las poblaciones que no los tu vieran, además de jueces de paz en pueblos pequeños y ranchos. Cabe señalar que a pesar de que en este decenio se dieron los dos procesos separatistas de Yucatán (1840-43 y 1846-1848) y se implantó una vez más el régimen central en el ínterin (1843-1846) se conservó la política federal en el sistema municipal, durante las separaciones y en las reincorporaciones al país (Tapia, 1985, p. 149). ${ }^{7}$

6 Los jueces de paz, si bien se impusieron inicialmente en 1832, no alteraron la estructura municipal federalista vigente desde la Constitución local y otros documentos legales de 1825, pues se añadieron a aquella, quedando un nivel por debajo de las juntas municipales y por encima de los alcaldes auxiliares. Hasta 1835 se implantarían en sustitución de estos últimos (Tapia, 1985, pp. 144-146).

7 Tapia (1985, p. 151) señala que "En 1843, a raíz de que el gobierno centralista de México acepta las condiciones de los federalistas yucatecos para su reincorporación al país -respeto al régimen municipal y al comercio locales, entre otras- Yucatán retorna a la república mexicana, después de haber estado separado de esta durante el periodo 184043. En particular, no ocurren cambios en el sistema municipal, pues la legislación federal que impuso en 1841 los ayuntamientos, alcaldes municipales y jueces de paz, continuó vigente a pesar de que la reintegración se realizó bajo el centralismo aún imperante en la nación. Asimismo, poco antes de la nueva separación yucateca (1846-1848) de México, es promulgada en septiembre 28 de 1846 la Ley Orgánica del Estado en la que se ratificó la política municipal federal yucateca". 
En la ley del 31 de marzo de 1841 es observable la amplitud de atribuciones de los ayuntamientos y sus alcaldes en el gobierno interior. En suma, sus funciones estaban relacionadas con el mantenimiento de la seguridad y el orden público, la salubridad, el cuidado urbano (construcción y limpieza de caminos, plazas, mercados, etcétera), los registros civiles (nacimientos, matrimonios y defunciones), la recaudación y administración de los caudales de propios y arbitrios y el establecimiento de escuelas de primeras letras (Aznar, 1849, pp. 102, 103).

El respetable sistema de justicia que implantó la Constitución yucateca de 1841 y la creación del Juicio de Amparo para el mundo, por uno de los más ilustres juristas en México don Manuel Crescencio Rejón, supondrían que en dicho territorio la legalidad y la procuración de justicia serían el sistema que imperaría con el pasar de los años. La consolidación de la política centralista en México para 1836, repercutiría en la decisión del Estado de erigirse como república en 1841. Bajo las bases de un código político propio, la vida independiente de la nueva república se vio determinada por una serie de sucesos sociales y económicos que hicieron afrontar uno de los hechos que más vidas ha cobrado a la historia de Yucatán: la Guerra de Castas.

Muy a pesar de que en el caso yucateco se instauró en la norma un sistema protector de los derechos fundamentales como el amparo, los mayas yucatecos fueron vendidos como esclavos a Cuba así lo revelan casos como el de Clemente Chan donde firmó:

Yo Clemente Chan declaro solemnemente que he convenido libre y voluntariamente en pasar a la isla de Cuba a la disposición de los Señores Goicouría y Hermano, para ocuparme de los trabajos que tengan a bien destinarme de aquella isla como colono, tanto en los trabajos agrícolas como en los domésticos o mecánicos, según la práctica del país; pudiendo ser este contrato traspasado a cualquier otra persona que juzguen convenientes los Señores Goicouría y Hermano, quedando obligado como si fuese con ellos mismos; y enterado de los reglamentos de colonización establecidos en la isla de Cuba, que se me han leído, me conformo en todas su partes, como también al decreto de mi Supremo Gobierno (AGEY, Fondo Poder Ejecutivo Contrato que firmaban los indígenas ante la Agencia de Colonización hacia Cuba en el que se disfrazaba su tráfico como esclavos, 1855, clausula 1).

Los jueces de paz debían conservar el orden público y "terminar amistosamente las riñas y diferencias que se susciten entre los vecinos"; podían arrestar a los delincuentes y los ebrios, y a su vez "no obligar a los indígenas a recibir dinero $o$ 
trabajo contra su voluntad, ni aun para amarrar barreras, tablados, enramadas y otros servicios” (Aznar, 1849, p. 107).

En Maxcanú se dictó un decreto de 14 de enero de 1848 con el fin de estipular los requisitos para ser juez de paz, primero se pedía que fueran ciudadanos en el ejercicio de sus derechos, mayores de veinticinco años, casados, de notoria honradez y probidad, saber leer y escribir. El documento estipulaba que a falta de vecinos que reunieran dichos requisitos podría aceptarse a los no casados e incluso los que no supieran leer y escribir, si no había vecinos con dichas cualidades, se señaló que podían "ser nombrados los indígenas que reúnan las expresadas circunstancias y en este caso serán considerados en la clase de los antiguos hidalgos" ${ }^{8}$

La organización municipal señalada no sufrió mayores cambios hasta la puesta en vigencia de la Constitución local de 1850, en la que nuevamente se impuso en la ley para el gobierno interior respectiva el binomio ayuntamientos-jueces de paz, siendo los miembros de los primeros electos de forma indirecta, y los segundos nombrados por el gobierno. Las atribuciones de los ayuntamientos continuaron siendo las mismas que en el reglamento anterior, pero las de los jueces de paz, evidentemente, se ampliaron de forma considerable, al

8 BVY: Número de ficha 8185, institución catalogadora CAIHY, clasificación local X-1846 -041, autor Nicolin, Decreto: Requisitos a cubrir para ser juez de paz, Maxcanú, 14 de enero de 1848, p. 1. suprimirse los alcaldes municipales precedentes; ahora, además de sus atribuciones en el ámbito de la justicia, debían velar por la policía y salubridad de sus pueblos, el establecimiento de escuelas de primeras letras, y en general ocuparon las facultades que antes tenían los dichos alcaldes municipales (Aznar, 1849, pp. 480-487).

Con la denominación de justicia de paz, el Estado designaba la actividad plegada por una rama de la administración de justicia a la que se encomendaba la resolución de aquellos casos, que, por su mínima cuantía, desde el punto de vista económico, exigían, de manera particular, brevedad y sencillez. La preocupación por simplificar los trámites judiciales fue una herencia del derecho castellano, en las Siete Partidas, se dispuso que puedan ser juzgados sin escritos los pleitos cuya cuantía no excediese de diez maravedíes, especialmente entre "hombres pobres y viles”. La Novísima Recopilación de Leyes de España prescribió que en los pleitos civiles que no excedieran de la cantidad de mil maravedíes no hubiera orden ni forma de proceso, ni solemnidad alguna, salvo que, habida la verdad sumariamente, la justicia procediera a pagar lo que se debiere. La Recopilación de Leyes de Indias también señaló la necesidad de respetar los usos y costumbres de los pueblos de indios en sus asuntos de justicia (De Pina y Castillo, 2010, pp. 531, 532). 
Durante la dictadura santanista en 1853 , se suprimieron la mayoría de los ayuntamientos, quedando únicamente vigentes los de las cabeceras de distrito (Mérida, Campeche, Valladolid, Izamal y Tekax). Sus funciones no se modificaron con respecto a las establecidas en los reglamentos anteriores. Debajo de estos se nombraron comisarios municipales, que se impusieron en todas las poblaciones donde no hubiera ayuntamientos, y a quienes se les otorgaron facultades idénticas a las de los ayuntamientos en sus poblaciones, es decir, la seguridad, la salubridad, las escuelas de primeras letras, el cuidado urbano, etcétera. Sus únicas restricciones eran que no podían formular ordenanzas municipales (Peraza, 2014, p. 56).

También es importante mencionar que los jueces de paz no fueron suprimidos a pesar de no aparecer como parte de la jerarquía política local en los reglamentos de 1853 y 1862, ya que su legalidad se sancionó en otros decretos, por ejemplo, en el de marzo de 1854 en el que se señalaba el número de jueces de paz que debía establecerse en cada departamento. Asimismo en junio de 1862 se redactó un decreto para el pueblo de Tahdziú, en el que se aseveraba que debía contar con un juez de paz propietario, un suplente y un comisario municipal, por lo que dicha figura se mantuvo en el marco de la estructura impuesta en los reglamentos de 1853 y 1862 aunque no aparezca en estos (Ancona, 1889, p. 534).
En el imperio de Maximiliano (18631867), la imagen del indígena mexicano fue primordial en la política que se pretendía implantar en la nación mexicana, es evidente que Maximiliano prefirió apoyarse en las glorias del pasado indígena por encima de la herencia española, para Maximiliano entre los mexicanos, los mejores "eran y seguirán siendo siempre los indios”. Mientras los gobiernos de México independiente se habían esforzado por ignorar las particularidades de los antes llamados naturales; el de Maximiliano ofrecía a los indígenas acceso especialmente a la autoridad (Pani, 1998, pp. 571-580).

La política imperial hacia los indios, tal como la política de los gobiernos liberales precedentes, tenía objetivos precisos que no tomaban en cuenta algunos derechos indígenas como el derecho a la propiedad comunal. La nación que pretendía construir el imperio era la idea liberal: una nación de individuos iguales ante la ley cuya economía era impulsada por la propiedad privada y el libre mercado. Si bien no podemos hablar de un sistema protector de las particularidades indígenas, sí de una política consciente de las desigualdades sociales que aquejaban desde tiempos coloniales (Pani, 1998, p. 598).

La política del Segundo Imperio rebasó los límites del liberalismo, para entrar en posturas de gran contenido social en donde el interés de la comunidad prepondera sobre el individual, situación que contras- 
ta con el liberalismo mexicano decimonónico, que con tal de homogeneizar a la población, no quiso reconocer la situación de vulnerabilidad de los indígenas; basta recordar la frase del famoso abogado Vallarta en una de sus sentencias: "los indios no forman parte del organismo nacional”. Así, las materias sobre las que legisló Maximiliano coinciden con lo llamado a la fecha derecho social, derecho laboral, derecho agrario y derecho de la seguridad social (Barroso, 1980, pp. 541-543).

Maximiliano se enfrentó a diversos movimientos indígenas, entre ellos, la rebelión yaqui en el norte y los mayas con la Guerra de Castas. En esta última, envió al comisario imperial Salazar Ilarregui, quien fue aprendido por un grupo de rebeldes, después de haber conseguido que otro se apaciguara. El comisario imperial fue macheteado por sus aprehensores (Barroso, 1981, pp. 265-266).

El indigenismo de Maximiliano le llevó a hacer publicaciones bilingües de sus leyes, en español y náhuatl; se le denominó al emperador "Huei Tlatoani”, es decir, Gran Rey o Gran Jefe, la intención en definitiva era dar a conocer las leyes a todos sus destinatarios. En materia agraria, se dictaron tres leyes de suma importancia: la ley para dirimir las diferencias sobre tierras y aguas sobre los pueblos, publicada en el número 261 del Diario del Imperio de 18 de diciembre de 1865; la Ley sobre terrenos de comunidad y de repartimiento; el Decreto sobre el fundo legal del 16 de septiembre de 1866 y dos Decretos expropiatorios; en esencia, dichas leyes procuraron a través de litigios, resolver unos de los problemas inherentes a las poblaciones indígenas, a quiénes les pertenece las tierras y los límites y propiedades de tierras comunales (Barroso, 1981, pp. 267-270).

La política de asistencia social, se plasmó en la Junta protectora de clases menesterosas, que tenía por objeto la mejoría de las clases sociales desfavorecidas, la junta proponía las medidas necesarias para mejorar la situación moral y material de la clases menesterosas, conforme a las quejas que se presentaren (Barroso, 1981, pp. 284).

La Junta sirvió para mitigar y canalizar el descontento de las agredidas comunidades de indios, que cuando menos pudieron ser oídos por las autoridades, cuestiones que leyes como la Ley Lerdo solo empobrecieron más a las comunidades (Arenal, 1990, p. 545). También existió un proyecto de la Junta que tuvo por objeto emancipar a los indígenas de la semiesclavitud en que se encontraban en las haciendas, estableciendo las relaciones entre propietarios y jornaleros, naturalmente que la idea causó gran alboroto (Barroso, 1981, p. 300).

Un ejemplo de la actividad de la Junta fue cuando solicitó que se diera a los indígenas la seguridad de que ninguna persona ni autoridad puede privarlos del goce de sus tierras y de que pueden transmitirlas a sus herederos y venderlas bajo ciertas 
condiciones, y esto será bastante para hacerlos apreciar debidamente la posesión de la propiedad particular. ${ }^{9}$

De 1876 a 1910 Porfirio Díaz dirigió los destinos del país; la corriente de los grandes códigos ya iniciada por Juárez es continuada y alrededor de ella hallamos muchas leyes: se crea el Código de Comercio, se reformaron diversos Códigos Civiles, Ley Orgánica de las Secretarías de Estado, Ley de Extranjería y Nacionalización de 1886, Ley de Vías de Comunicación y Aguas de 1894 y la Ley Orgánica del Ejercito Nacional de 1900, entre otras. Posteriormente vendría el movimiento revolucionario y consecutivamente la Constitución de 1917, estableciendo los derechos sociales como el del trabajo y en materia de propiedad.

Eiss (2010) señala que la idea de pueblo mantiene continuidades desde la época colonial, pues el propio "pueblo" es quien cobraba relevancia en las cuestiones de justicia, no solo lo político que rodea al pueblo, sino precisamente lo social que incluye a actores de diversos rangos desde la sociedad que clamaban justicia hasta los oficiales de más alto rango que la aplicaban, todo ello ha formado parte de un derecho maya que en esencia fue reconocido por el derecho positivo durante la colonia por el Imperio Español y que a posteriori los propios usos y costumbres que se han reconocido en la Constitución Política de los Estados Unidos Mexicanos.

9 AGN, Gobernación, legajos vol. 1144(1), exp. 1.
Durante la Revolución se impone la ideología del nacionalismo revolucionario en un discurso indígena que exalta las culturas prehispánicas y las incorpora en la simbología de la nación mexicana; el Estado promovía políticas de asimilación cultural vía el mestizaje. En Yucatán, la visión indigenista en el gobierno de Felipe Carrillo Puerto de 1922 a 1924, reivindica los derechos de los campesinos y de los mayas; según el mismo, el objetivo de la Revolución en Yucatán, es "dar al indio maya su estatus de hombre libre, redistribuir las tierras comunes y ejidos”. Impulsó la enseñanza de la lengua maya en las escuelas para enfatizar la riqueza y gloria de la antigua civilización (Castellanos, 2003, p. 59).

De hecho, la oralidad como elemento esencial de la justicia maya, se preservó a tal punto que en cuestiones de tierras para 1922, la Comisión Nacional Agraria empezó a enviar ingenieros a Yucatán con el fin de recolectar títulos de propiedad, los cuales en muchos casos no existían y fueron aceptados testimonios orales con el fin de poder hacer un nuevo mapa del llamado reparto agrario en la zona (Eiss, 2010, p. 150).

Mediante el flujo de capitales hacia los hacendados, parafraseando a Quezada, en menos de 30 años Yucatán se convirtió en uno de los estados más prósperos y ricos de México (2016, p. 140).

Por su parte, Lizama y Bracamonte (2014, pp.11-12) describen algunas de las situaciones que en correlación con la moderniza- 
ción que han transformado los últimos años a la población maya son "la desincorporación de los ejidatarios del crédito agrícola de Yucatán hacia los años setenta del siglo XX, que significó un elevado crecimiento en el desempleo rural en la población maya”. A su vez, el crecimiento de escuelas técnicas en zonas y comunidades maya hablantes, y el desarrollo de la industria maquiladora en zonas mayas. Estos autores sostienen que el proyecto social del pueblo se ha fracturado, pues dicha cultura ha quedado sujeta a un proyecto nacionalista y de colonización interna, donde los indígenas no encajan en el ambiente (Lizama \& Bracamonte, 2014, pp. 19-25).

La forma de hacer justicia en los municipios de Yucatán es diversa, influenciada por la tradición jurídica de la colonia y el siglo XIX; como se mencionó anteriormente, en el Estado existen jueces de paz y conciliación. La práctica de justicia maya tiene como elementos la cohesión comunitaria y la armonía social (Lizama y Bracamonte, 2014, pp. 48, 51).

En el mismo orden de ideas, Baños (2003, pp. 17, 25, 70) apunta que la cultura moderna trastocó las instituciones, costumbres e identidades de la población yucateca a finales del siglo XX. Cuando se liga el concepto moderno a lo rural es menester referir que lo rural está asociado a una sociedad de menos de 25000 habitantes, organizada en torno al aprovechamiento de los recursos naturales y una cultura agraria. La población y el desarrollo económico yucateco se ha sustentado fundamentalmente en la industrial henequera que tuvo auge a inicios del siglo XX; no obstante, un gran sector del Estado basó su economía en la agricultura tradicional. A finales del siglo XX en 1994, la aparición del Ejercito Zapatista de Liberación Nacional (EZLN) fue detonante para que se ampliara el reconocimiento de los derechos de los pueblos indígenas; la firma de los Acuerdos de San Andrés de 1996 permitieron superar el paradigma de exclusión constitucional (González, 2010, pp. 470). Los acuerdos señalados solicitaron reformas constitucionales para garantizar la autonomía de los pueblos indígenas, preservar sus lenguas, legislar por parte de los Estados en torno a la libre determinación de los pueblos originarios, la necesidad de reconocer las identidades propias, las formas de gobierno internas, las formas de organización política, económica y cultural, nadie puede poner en duda que los acuerdos representaron un salto tremendo en materia de derechos indígenas.

Actualmente, con la reforma constitucional en materia de derechos humanos del 2011, se amplió el marco de derechos fundamentales, creándose una revolución jurídica que incorporó los tratados internacionales al rango constitucional de protección de derechos humanos, y que puso sobre la mesa la valoración de tratados internacionales como el 169 del OIT y la 
Declaración Universal de los Pueblos Indígenas del 2007, que deben ser interpretados de forma amplia en concordancia con el artículo 4 de nuestra Constitución y que obligan a las entidades federativas mexicanas a regular leyes de pueblos indígenas de forma amplia que protejan sobre todo el derecho humano a la libre determinación de los pueblos originarios. Cuestión que es una tarea aún pendiente en el marco jurídico mexicano.

\section{Metodología}

Como se expresó en la introducción de este trabajo, hacer el estudio de los cambios y continuidades de la justicia maya desde la época prehispánica hasta la época del Estado nacional mexicano implica un ejercicio histórico de larga duración, en el que se recurrió a la revisión de la bibliografía sobre el tema y de fuentes de archivo. La metodología histórica de larga duración, como diría Braudel, consiste en "lo que el historiador de las civilizaciones puede afirmar, mejor que cualquier otro, es que las civilizaciones son realidades de muy larga duración", ello combinado con el uso de método etnohistórico alcanzamos entender problemas actuales tanto desde el derecho, antropología, sociología u otros temas recientes de la sociedad yucateca, es fundamental comprenderlos con la forma de historiar de la larga duración, concepto que a propuesta de Brau- del es un puente de comunicación entre las diferentes disciplinas de las ciencias sociales, para poder exponer con mayor claridad las prácticas de los actores e instituciones en diferentes momentos históricos (Braudel, 1968, p. 187). Consideramos que a partir de esta metodología de larga duración podemos dar cuenta de lo que se considera como justicia maya en el devenir histórico; además, con el cruce de fuentes primarias y bibliográficas recreamos la justicia maya a través del tiempo; el método comparativo se incorpora en este estudio, para comprender las similitudes y diferencias entre cada periodo histórico de la justicia maya.

\section{Resultados y discusión}

La mirada histórica de la justicia maya nos permite entender cambios y continuidades en torno a diferentes problemáticas que enfrentan los mayas yucatecos en la actualidad. Muchos estudios se han realizado sobre la forma en que se entienden y resuelven conflictos jurídicos, por las sociedades mayas y de otros grupos étnicos, suelen dividirse en dos grupos, el primero se acerca al análisis de sistemas normativos propios y la forma en que se resuelven problemas dentro de la comunidad conforme a los usos y costumbres, en este sector encontramos los estudios de Esteban Krotz, Israel Herrera y Manuel Buenrostro, el segundo sector se circunscribe en el análisis de la protección de de- 
rechos humanos colectivos contemplados en el máximo ordenamiento legal mexicano, donde resultan de gran importancia los estudios de González Galván, Rodrigo Llanes y Jorge Fernández, investigaciones que se avocan a interpretar derechos difusos y las formas como se expresan desde los movimientos sociales y en la praxis jurídica, nos muestran cómo las comunidades desde la acción sociojurídica rompen con la lógica de la relatividad de las sentencias de amparo. Los derechos humanos, protegidos en los artículos $2 .^{\circ}$ y $4^{\circ}$, donde se establece del derecho a la libre determinación de comunidades indígenas que asegure la unidad nacional y la protección a un medio ambiente sano, con base en los principios de la sustentabilidad, principios jurídicos que buscan una protección colectiva que en la mayoría de los casos van contra la lógica del mercado, de igual forma se expresa la protección en leyes generales, tal es el caso del artículo 15 de la Ley General de Equilibrio Ecológico y protección al Ambiente, que en fracción XIII señala que se observarán el principio de "garantizar el derecho de las comunidades, incluyendo a los pueblos indígenas, a la protección, preservación, uso y aprovechamiento sustentable de los recursos naturales y la salvaguarda y uso de la biodiversidad, de acuerdo a lo que determine la presente Ley y otros ordenamientos aplicables" (LGEEPA). Justamente en estos estudios se ha cuestionado el papel de las instituciones del Estado para la protección y salvaguarda de estos derechos humanos, y se ha puesto énfasis en procesos de lucha y conquista basado en experiencias mediante la adecuada defensa a través de los mecanismos de protección de los derechos humanos, como el juicio de amparo.

Para la primera dimensión de estudios, podemos referir conceptos claves que se han desarrollado en la investigación de la justicia maya, verbigracia Manuel Buenrostro (2015, p. 47), quien señala para el caso de Quintana Roo, complicado de definir el concepto de justicia maya desde una sola dimensión, pues la misma responde particularidades sociales y jurídicas que se relacionan en dinámicas, significados y prácticas concretas, además, que "los distintos órdenes legales producto de formas coloniales de dominación se imbrican en relaciones dinámicas y tensión" (p.46) lo anterior es para el autor fundamental para entender cómo se ejerce el derecho para las autoridades mayas de la región.

Por su parte, Esteban Krotz (2015, p. 199) habla de cómo se han banalizado conceptos como el de diálogo cultural, empleado para fines políticos de los agentes hegemónicos quienes deciden el curso de acciones y leyes del pueblo maya, y que deja a un lado las diferentes posiciones sociales del pueblo maya, derivado de la desigualdad, racismo y exclusión social que ha padecido a lo largo de la historia. Israel Herrera (2015, p. 177) ha hecho énfasis en el tópico 
de la diferencia cultural como un elemento de la prueba pericial antropológica, la cual permite entender la pertenencia de un grupo indígena o las costumbres reconocidas y practicadas por la persona, esta prueba sirve para comprender prácticas ancestrales y dotar al juzgador de mejores elementos para poder resolver conflictos jurídicos, donde esté por medio el derecho indígena, lo que la hace de especial relevancia para la protección de los derechos humanos consagrados en el artículo 2. ${ }^{\circ}$ constitucional.

En la segunda vertiente de estudio, las investigaciones de Rodrigo Llanes (2019, p. 124) exponen como tema que los derechos humanos del pueblo maya no se habían impulsado desde el enfoque de los derechos colectivos, no obstante, a partir de las lógicas de desarrollo inmobiliario, despojo y afectación del medio ambiente, se hizo imprescindible que diversos colectivos y organizaciones de la sociedad civil promuevan amparos y recursos jurídicos en aras de la reivindicación de derechos, tomando como base las garantías protegidas en el artículo 2. ${ }^{\circ}$ constitucional, como la consulta libre, previa e informada; sin embargo, no ha sido suficiente pues no existe propiamente una regulación procesal concreta para poder exigir las consultas. González Galván (2019, p. 17) habla de la importancia de que los pueblos y comunidades indígenas no solo tenga derecho a desarrollar su cultura, "sino también tie- nen derecho a decir su derecho (a ejercer su juris dictio, su jurisdicción): tienen derecho al derecho".

De nuestra parte, en algunas investigaciones hemos referido cómo han surgido leyes estatales que en teoría deberían generar los mecanismos para la protección de los derechos humanos de poblaciones mayas, tal es el caso de la Ley del Sistema de Justicia Maya de 2014 del estado de Yucatán, que fue creada sin que mediara consulta al pueblo maya, lo cual refleja cómo se crea el derecho desde las élites a la cual no pertenece el pueblo maya.

El estudio que presentamos da cuenta de muchos de los problemas relatados, y sin una debida mirada histórica, resulta imposible comprenderlos en la actualidad. Consideramos que, de igual forma ha faltado articular el conocimiento de los derechos de los pueblos indígenas no únicamente desde la esfera constitucional, sino que es menester revisar las legislaciones locales como códigos civiles, penales, familiares entre otros, que vayan en concomitancia con la Carta Magna, para poder empezar a hablar de un sistema jurídico eficiente en cuanto a la protección de los derechos humanos, a la libre determinación de comunidades mayas en su integridad.

\section{Conclusiones}

Del estudio expuesto, se pone en relieve la importancia que tuvieron los cambios en el tiempo en la justicia maya en Yuca- 
tán a través de dos grandes coyunturas: la conquista y la formación del Estado nacional. Como bien habíamos advertido, el pasar del tiempo llevó al sistema de justicia prehispánico a reinventarse a través de la imbricación de las normas indianas, castellanas y nacionales. La historiografía nos dio la pauta para conocer aspectos de la forma de obrar del batab antes de la llegada de los españoles y de un sistema jurídico que estaba ligado a una serie de sanciones severas para algunos, como la pena de muerte o la esclavitud.

El impacto de la conquista y de la creación del Estado nacional sobre los pueblos de "indios" se manifestó generando un nuevo orden de derecho que ha requerido, en el caso de Yucatán, de un largo periodo de tiempo para un reconocimiento desde el punto de vista del derecho positivo, pues no fue hasta el año 2011 con la Ley para la Protección de los Derechos de la Comunidad Maya del Estado de Yucatán y con la consecutiva Ley del Sistema de Justicia Maya del 2014, que se plasmó en la legislación yucateca.

A manera de síntesis, podemos decir que el presente artículo nos sirve como un marco histórico para entender la justicia que opera en las comunidades mayas en la actualidad, a partir de lo anterior pretendemos entrelazar los eventos que influyeron en las leyes, procedimientos y la forma de ejercer la justicia, que conforme a la misión civilizadora de la Constitución y otras instituciones, surge el dilema, respecto a si podemos hablar de una justicia maya, o de la visión propia del Estado plasmada en leyes, tal como es el caso de las nuevas leyes que definen lo maya y a sus actores.

En este sentido, el calificativo maya se extiende/aplica a la justicia en sí (como función) y al juez. Esto hace relevante destacar cómo es entendido el concepto justicia entre los mayas en confrontación con su concepción occidental y liberal, y cómo es concebido el juez y otros actores, como las funciones que desempeñan, si aún podemos distinguir una justicia genuinamente maya, no obstante, el dilema mencionado.

De tal forma que, a partir del advenimiento de nuevas leyes, resulta un choque intercultural e interlegal que tiende a trastocar tradiciones y prácticas. Las nuevas legislaciones tienden a dejar como membrete la justicia maya, que consideramos la nulifican y convierten la misma.

\section{Referencias}

Ancona, E. (1889). Colección de leyes, decretos, órdenes y demás disposiciones de tendencia general expedidas por el poder legislativo del Estado de Yucatán, formada con autorización del gobierno. Mérida, Yucatán: Imprenta el Eco del Comercio.

Archivo Digital de la Legislación de Perú (1680). Recopilación de Leyes de Indias de 1680. Lima: ADLP. 
Arenal, J. (1990). La protección del indígena en el Segundo Imperio Mexicano: la Junta Protectora de las Clases Menesterosas. Revista Chilena de Historia del Derecho, 521-544.

Aznar, A. (1849). Colección de leyes, decretos y órdenes o acuerdos de tendencia general del Poder Legislativo del Estado libre y soberano de Yucatán. Mérida, Yucatán: Imprenta Rafael Pedrera.

Baños, O. (2003). Modernidad, imaginario $e$ identidad rurales. El caso de Yucatán. México: El Colegio de México.

Barroso, A. (1980). Maximiliano: legislador liberal. Reflexiones sobre el Segundo Imperio. En J. Soberanas, Memoria del II Congreso de Historia del Derecho Mexicano (pp. 539-555). México: UNAM jurídicas.

Barroso, A. (1981). El indígenismo legislativo de Maximiliano. Jurídica, Universidad Iberoamericana, 257-303. Jurídica, Universidad Iberoamericana, 257-303.

Bolio, H., y Bolio, J. (2017). Análisis de la justicia de los jueces de paz en los municipios de Chacsinkín y Tahmek, Yucatán. Ciencias Sociales y Humanidades Vol. 4, Núm. 2, 49-64. Bolio, J. (2012)., De las Justicias Indígenas a las justicias castellanas: dinámica del proceso judicial en la jurisdicción de Quetzaltenango, Guatemala (1700-1750). Tesis de maestría. Mérida, Yucatán: CIESAS Peninsular.

Borah, W. (1996). El juzgado general de indios en la Nueva España. México: Fondo de Cultura Económica.
Bracamonte, P., y Solís, G. (2005). Rey Canek. Documentos sobre la sublevación maya de 1761. México: CIESAS-UNAM-ICY.

Braudel, F. (1968). Aportación de la historia de las civilizaciones: La historia y las ciencias sociales. Madrid: Alianza.

Buenrostro, M. (2015). La justicia en manos de jueces indígenas mayas: balance de una década de la ley de justicia indígena de Quintana Roo. En E. Krotz, Sociedades mayas y derecho (pp. 37-56). Mérida: Instituto de Investigaciones Antropolígicas, UNAM, PROIMMSE, Universidad Modelo.

Cunill, C. (2012). Los defensores de indios de Yucatán y el acceso de los mayas a la justicia colonial (1540-1600). Mérida, Yucatán: UNAM, Centro Peninsular en Humanidades y Ciencias Sociales.

De la Garza, M. (2008). Relaciones histórico-geográficas de la gobernación de Yucatán. Mérida, Valladolid y Tabasco. México: UNAM.

De Landa, D. (2012). Relación de las cosas de Yucatán. Madrid: Linkgua digital.

De Pina, R., y Castillo, J. (2010). Instituciones de Derecho Procesal Civil (29 ed.). México: Porrúa.

Eiss, P. (2010). In the Name of el Pueblo. Place, comunity and the politics of History in Yucatán. Londres: Duke University Press.

González, J. (2010). El Estado, los indígenas y el derecho. México: UNAM Jurídicas.

González, J. (2019). Manual de Derecho Indígena. México: FCE, IIJ UNAM.

Guemez, P. (2007). La emergencia de los ayuntamientos constitucionales gaditanos y la 
sobrevivencia de los cabildos mayas yucatecos 1812-1824. En J. Ortiz, y J. Serrano, Ayuntamientos y liberalismo gaditano en México (pp. 60-103). México: El Colegio de Michoacán, Universidad Veracruzana.

Izquierdo, A. (1981). El delito y su castigo en la sociedad maya. En UNAM, Memoria del II Congreso de Historia del Derecho Mexicano (pp. 57-68). México: UNAM, Instituto de Investigaciones Jurídicas.

Krotz, E. (2015). Relaciones interculturales, la legislación de los derechos indígenas en Yucatán y los derechos humanos. En E. Krotz, Sociedades mayas y derecho (pp. 185-202). Mérida: IIA UNAM, PROIMMSE, Universidad Modelo.

Lizama, J., y Bracamonte, P. (2014). Decir que somos quien somos. Compendio de resultados de encuestas a población maya de la península de Yucatán. México: Raíz de sol.

Llanes, R. (2019). No solo los ejidatarios tienen derechos. La emergencia de los derechos humanos de los mayas de Yucatán. Penínsulavol. 14, núm. 1, 107-129.

Marino, D. (2006). Ahora que Dios nos ha dado padre. El segundo imperio y la cultura jurídico-política campesina en el centro de México. Historia Mexicana, vol. 55 núm 4, 13531410.

Pani, E. (1998). ¿"Verdaderas figuras de Cooper" o "pobres inditos infelices"? La política indigenista de Maximiliano. Historia Mexicana, Colegio de México, 571-604.

Peraza, Y. (2014). Un escándalo en el orden liberal. La restitución de las repúblicas indigenas en Yucatán, 1841-1868. Tesis de maestría. Mérida: CIESAS, Peninsular.

Quezada, S. (2016). Historia breve de Yucatán. Mérida: Fondo de Cultura Económica.

Salcedo, A. (2009). El derecho maya prehispánico, un acercamiento a su fundamentación socio-política. Alegatos, UAM, 155-178.

Solís, G. (2013). Solís Robleda, G. (2013). Entre litigar justicia y procurar leyes. La defensoría de indios en el Yucatán colonial. Mérida, Yucatán: CIESAS, colección Peninsular, Porrúa. Speckman, G. (2006). Los jueces, el honor y la muerte. Un análisis de la justicia (Ciudad de México, 1871-1931). Historia Mexicana (4). Colegio de México, 1411-1466.

Tapia, C. (1985). La organización política indígena en el Yucatán independiente, 1821-1847. Tesis de Licenciatura. Mérida: UADY. 